\title{
Risk of Infections in Adult Patients with Haematological Malignancies
}

\author{
Mette Nørgaard*
}

Department of Clinical Epidemiology, Institute of Clinical Medicine, Aarhus University Hospital, Denmark

\begin{abstract}
Patients with haematological malignancies are at increased risk of infections not only because of the malignancy itself but also because of neutropenia induced by intensive chemotherapeutic treatment, and the cytotoxic effect on the cells that line the alimentary tract. In haematological malignancy patients with a compromised inflammatory response, the classic signs and symptoms of infection may be masked. The results of blood cultures therefore play an important diagnostic role. Bacteraemia is a relatively common serious complication occurring in around $15 \%$ of patients with haematological malignancies within the first years after diagnosis but the risk varies between different types of haematological malignancies. Other risk factors for bacteraemia are presence of mucositis, neutropenia, and use of central venous catheters. Invasive fungal diseases are also serious infectious complications in this population. Viral infections are particularty often in patients that have received a bone marrow transplant. Future work in this field could focus on potential modifiable risk factors and on how time since haematological diagnosis may influence risk of infection.
\end{abstract}

Keywords: Infection, bacteremia, neutropenia, haematological cancer, adults, epidemiologic factors.

\section{INTRODUCTION}

Infections remain a common complication in patients with haematological malignancies. These patients are at increased risk of infections not only because of the malignancy itself but also because of neutropenia induced by intensive chemotherapeutic treatment that may be followed by haematopoietic stem cell transplantation, and the cytotoxic effect on the cells that line the alimentary tract [1]. This review focuses on the risk of different types of infections in adults with haematological malignancies.

\section{FEBRILE NEUTROPENIA}

Febrile neutropenia is a medical emergency prompting immediate hospitalisation in most cases for assessment and treatment. The definition of febrile neutrpenia varies but is generally regarded as presence of a fever $>38^{\circ} \mathrm{C}$ with an absolute neutrophile count $<1.0 \times 10^{9} / \mathrm{L}$ [2]. Neutrophils make up over $90 \%$ of the circulating granulocytes in a normal individual and serve as the body's primary defence against infections [3]. In a seminal study from 1965, Bodey et al. [4] followed 52 patients aged 1-77 years with a newly diagnosed acute leukaemia and found that the incidence of infectious episodes decreased with increasing levels of circulating granulocytes and lymphocytes. Fever and infections as a consequence of neutropenia mainly in acute leukaemia or agranulocytosis, were first described about 100 years ago [5]. In the 1960s, the attention to severe infections among patients with haematological or other malignancies increased, due to better antineoplastic treatment. Specific pathogens, such as Pseudomonas aeruginosa and Serratia marcescens, were recognised as specific challenges in

*Address correspondence to this author at the Department of Clinical Epidemiology, Institute of Clinical Medicine, Aarhus University Hospital, Denmark; Fax:+4587162215; E-mail:mn@dce.au.dk oncologic treatment $[6,7]$. At that time, mortality following P. aeruginosa bacteraemia was approximately $90 \%$, in spite of the availability of antibiotics active in vitro [8]. According to PubMed, the term "empiric antibiotic therapy" was used for the first time in 1971 by Schimpff et al. in a paper on febrile patients with cancer and granulocytopenia [9]. The authors launched the concept that a combination of antibiotics active against $P$. aeruginosa and other Gramnegative bacilli should be given empirically as soon as neutropenic patients become febrile. In 1973 in Europe, the group of Klastersky at Jules Bordet Institute in Brussels initiated a series of randomised controlled multicenter trials under the auspices of The International Antimicrobial Therapy Cooperative Group of the European Organisation for Research and Treatment of Cancer (EORTC) [10-14]. These trials focused on finding the most superior antibiotic combination for empirical treatment. In the EORTC trials, the results were primarily evaluated based on patients with positive microbiological findings, which further focused the attention to patients with bacteraemia. In a EORTC-trial including 859 febrile neutropenic cancer patients, 218 (29\%) of the patients had bacteraemia and 25 (3\%) had microbiological documented infection without bacteraemia [15]. Because of the high mortality in patients with febrile neutropenia hospital treatment with close medical surveillance and ready availability of emergency care is considered crucial [16]. Neutropenic patients with fever are, however, a heterogeneous population with subsets of patients who have low risk of medical complications. Therefore attention has been paid to risk assessment models with the purpose of identifying patients with low risk who could be safely discharged to receive antibiotics at home [16]. Talcott et al. developed a prediction rule which classified inpatients, outpatients with serious comorbidity, and patients with uncontrolled cancer as high risk patients. Additional risk factors were age 40 years or greater and short latency from chemotherapy to fever and neutropenia [16]. Klastersky et 
al. developed the multinational association for supportive care in cancer (MASCC) risk index based on a derivation cohort of 756 patients and validated in a cohort of 383 patients with febrile neutropenia [17]. Predictive factors were a burden of illness indicating absence of symptoms or mild symptoms (weight, 5); moderate symptoms (weight, 3); absence of hypotension (weight, 5); absence of chronic obstructive pulmonary disease (weight, 4); presence of solid tumour or absence of previous fungal infection in patients with haematologic malignancies (weight, 4); outpatient status (weight, 3); absence of dehydration (weight, 3); and age less than 60 years (weight, 2). Scores $\geq 21$ identified patients with low risk [17]. This index has since then been validated in other populations [18, 19]. According to the Infectious Diseases Society of America (IDSA) Clinical Practice Guideline for the Use of Antimicrobial Agents in Neutropenic Patients with Cancer risk stratification is a recommended starting point for managing patients with fever and neutropenia [20].

\section{BACTERAEMIA}

Focal infections, such as pneumonia, acute cystitis, or perianal abscesses, occur in patients with haematological malignancies [21]. However, because of the compromised inflammatory response in these patients, the classic signs and symptoms of infection may be masked [22]. An elevated temperature may be its only clinical sign; thus, the results of blood cultures play a pivotal diagnostic role.

Whereas Gram-negative bacteria (Escherichia coli, Klebsiella spp, and P. aeruginosa) were predominant in neutropenic cancer patients in the 1970 s and early $1980 \mathrm{~s}$ [23], Gram-positive bacteria (coagulase-negative staphylococci and viridans streptococci) became progressively prevalent in the late 1980s and early 1990 s [24]. Some of the factors implicated in the increasing number of Gram-positive bacteraemias were the administration of aggressive chemotherapy and radiotherapy regimens that induced severe mucositis, increased use of indwelling catheters, the widespread use of fluoroquinolones as prophylactic agents, and empirical antibiotic treatment with high activity against Gram-negative infections [25-27]. Yet, this shift towards Gram-positive bacteraemias has not been global. Chen et al. demonstrated in 7058 patients admitted to the haemato-oncological department at National Taiwan Hospital between 2002 and 2006 that $60 \%$ of the bacteraemias in neutropenic patients were caused by Gramnegative infections [28] and a similar pattern was demonstrated by Gupta et al. in a study from India [29].

The change in spectrum of microorganisms causing bacteraemia has likewise been more unequivocal in studies including non-neutropenic haematological patients as well [24]. These differences show that reliance solely on data on bacteraemias from other countries/institutions may be misleading and emphasise the need for frequent monitoring and surveillance at institutions treating large numbers of patients with neutropenia $[30,31]$.

Moreover, increasing rates of drug resistance among both gram-positive and gram-negative pathogens are being documented globally [26, 32, 33]. This includes methicillinresistant Staphylococcus aureus (MRSA), vancomycinresistant enterococcus (VRE), extended-spectrum beta- lactamase (ESBL) -producing gram-negative bacteria, and carbapenemase-producing organisms, including Klebsiella pneumoniae carbapenemase (KPC) [20].

The administration of parenteral, broad-spectrum empirical antibiotic therapy after hospitalisation of patients with febrile neutropenia is the accepted standard of care [20]. Risk assessment may determine the type of empirical antibiotictherapy (oral vs intravenous), the venue of treatment (inpatient versus outpatient), and duration of antibiotic therapy. Drug resistance must, however, also be taken into consideration when prophylaxis and empirical therapy are being considered. One strategy consists of maximising initial empirical coverage with subsequent reduction or streamlining (de-escalation) of the regimen based on clinical and microbiological data [30]. Another strategy could be to restrict use of e.g. use of third generation cephalosporins or carbapenems which are associated with high risk of promoting multidrug resistance. However, it may not be practical to restrict several classes of drugs in order to reduce the emergence of resistance [30]. Instead equal use of multiple classes of antimicrobial agents has been suggested and successfully used e.g. in the the M. D. Anderson Cancer Center [30].

Since purulence, fluctuation, or lung infiltrates may not develop in patients with haematological malignancies the focus of bacteraemia often remains unknown [34]. Failure to determine the source of infection is associated with increased mortality in patients with bacteraemia [34]. At the same time, Pittet et al. found that pneumonia as a source of infection was associated with increased mortality in nosocomial bloodstream infections [35]. Likewise, Gonzales-Barca et al. found that pneumonia - defined as the presence of acute respiratory illness and pulmonary infiltrate - as the focus of bacteraemia was associated with a higher risk of mortality among neutropenic patients (OR, 4.4 (95\% CI: 1.9-10)) [36]. In the latter study, however, the authors did not address the impact of an unknown focus. For patients with haematological malignancies bacteraemia is widely regarded as a major risk factor for mortality [1]. A population-based study from Denmark included 7456 patients, who were admitted to hospital with their first episode of bacteraemia. Of these, 444 patients had a haematological malignancy. Compared with patients without a malignancy diagnosis patients with a haematological malignancy had a higher mortality (adjusted mortality rate ratio $=1.6(95 \% \mathrm{CI}, 1.3-2.0)$. Their mortality did not differ substantially from the mortality in patients with other types of malignancies [37].

\section{HAEMATOLOGICAL MALIGNANCIES INCIDENCE OF BACTERAEMIA}

AND

Little formal epidemiological evidence exists on the magnitude of the incidence of bacteraemia among patients with haematological malignancies. One study, reported in Spanish by Teira et al., computed incidence rates of bacteraemia among haematological patients admitted at one haemalogical department [38]. Of the 244 newly diagnosed cases of acute myeloid leukaemia or lymphoma 53 admitted patients were lost to follow-up. In the remaining 191 patient the incidence rate of bacteraemia, expressed as cases per 1000 patient-days, was 5.8 for AML and 0.21 for high-grade 
malignant lymphoma [39]. In a Danish study Nørgaard et al. found that among 1,666 patients with a first haematological malignancy, $358(21 \%)$ had a successive episode of bacteraemia during a mean follow-up of 2.2 years, yielding an overall incidence rate of 96 per 1000 years [34]. In 246 $(15 \%)$ of the patients the first episode of bacteraemia occurred within a year after haematological malignancy diagnosis. The cumulative incidence of bacteraemia did, however, differ between the different types of haematological malignancies within the first year of follow-up. When compared with Hodgkin's disease patients, the incidence rate ratios [IRRs] for bacteraemia were 23.3 (95\% CI: 10.0-54.5) for acute myeloid leukaemia, 3.8 (95\% CI: 1.5-9.3) for multiple myeloma, 2.2 (95\% CI: 0.9-5.1) for non-Hodgkin lymphoma or chronic lymphatic leukaemia, and 8.3 (95\% CI: 3.5-19.6) for others, all adjusted for age, gender, and comorbidity [34]. Similarly, in an American study including 365,014 patients hospitalised with haematological malignancies, of whom 64,684 developed severe sepsis the relative risks (RRs) of severe sepsis showed large variation between the different types of haematological malignancies, with Hodgkin's disease having the smallest $(\mathrm{RR}=4.1)$, and acute myeloid leukaemia the largest risk of severe sepsis $(R R=65.2)$ [35].

\section{RISK FACTORS FOR BACTERAEMIA IN PATIENTS WITH HAEMATOLOGICAL MALIGNANCIES}

Other factors than type of haematological malignancy may influence the risk of bacteraemia in patients with haematological malignancies. In a case-control study by Pagano et al., use of central venous catheter (OR 6.1(95\% CI: 1.3-12.3)) and neutropenia for more than six days (OR 3.0 (95\% CI: 1.7-9.5)) were found to be risk factors for bacteraemia in patients with haematological malignancies [40]. In a study of 104 patients with haematological malignancies and 253 patients with solid tumours Pedersen et al. found that after placement of their first central venous catheter device patients with haematological malignancies had 10-fold increased risk of bacteraemia compared with patients with solid tumours $(\mathrm{RR}=10.8$ (95\%; CI, 5.8-20.1)) [41]. Ruescher et al. conducted a case-control study among recipients of autologous bone marrow transplantation and found patients with ulcerative mucositis to be three times as likely to develop alpha-hemolytic streptococcal bacteremia as those without ulcerative mucositis $(\mathrm{OR}=3.02)$ [36]. In a randomised controlled trial among neutropenic cancer patients Bucaneve et al. found prophylactic use of flourquinolones to be associated with an absolute decrease in risk of bacteraemia, risk difference -0.16 (95\% CI: -0.22 to 0.09) [42].

Apostolopolou et al. computed incidence rates of bacteraemia among 102 patients with haematological malignancies who were hospitalised for more than 48 hours [43]. They found an overall bacteremia incidence of 21.99 per 1000 patient days at risk. The patients who developed bacteraemias were mainly women. In contrast, age did not seem to predict bacteraemia [43]. Garcia-Suarez et al. also found similar rates of infection in elderly and in younger haematological cancer patients with febrile neutropenia in a study of 131 consecutive episodes of fever and chemotherapy-induced neutropenia in 85 adults with haematological malignancies [43]. Age is, however, shown to be a risk factor for development of severe neutropenia [1].
Few, if any, data exist on the impact of comorbidity as a risk factor for bacteraemia in patients with haematological malignancies.

\section{CANDIDAEMIA}

Although the incidence of invasive candida infections has decreased with the prophylactic use of azole drugs that was introduced in the 1990's candidemia remains a serious disease in patients with haematological malignancies. At the M.D. Anderson Cancer Center the incidence of candidemia per 100,000 in-patients days varied between 13.9 and 23.2 in the period 2001 to 2006 [44]. Marr and colleagues found a cumulative incidence of candidemia of $4.6 \%$ following bone marrow transplantation [37]. Over time, candidemia strains have shifted from Candida albicans toward non-albicans species such as C. krusei, C. glabrata, C. parapsilosis, and C. tropicalisis [44]. The candidemias are most often acquired endogenously through invasion of the gastrointestinal tract [45] or as a catheter-related infection [44]. According to the IDSA guidelines, empirical antifungal coverage should be considered in high-risk patients who have persistent fever after 4-7 days of a broad-spectrum antibacterial regimen and no identified fever source [20].

\section{RESPIRATORY TRACT INFECTIONS}

In a Turkish study including 1,132 patients with haematological malignancies who were referred to an infectious disease team for suspected infection, pneumonia was detected in 173 cases and was the most common clinically documented infection [46]. Still, no formal epidemiological data exist on the incidence of pneumonia in patients with haematological malignancies. Pulmonary complications are particular common following haematopoietic stem cell transplantation. Puig et al. identified 49 episodes of pneumonia in 326 adult Spanish patients who underwent autologous stem cell transplantation from 1990 to 2005[47]. Multiple myeloma and neutropenia lasting for more than 7 days predicted a higher risk for pneumonia. No pathogen could, however, be isolated in 38 $(76 \%)$ of these cases [47].

Respiratory syncytial virus, Influenza A and B viruses, and parainfluenza viruses are all widely described as causes of severe respiratory infections in patients with haematological malignancies [48]. But also human enterovirus and human rhinovirus respiratory tract infections are in a Spanish study described as being relatively common in haematological patients [49].

In the recent years focus has been on severity of influenza in patients with haematological malignancies. In a study including 100 immunocompromised patients hospitalised with upper respiratory tract infection due to Influenza a haematological malignancy diagnosis predicted a high risk of progression to pneumonia [50]. Although, the utility of influenza vaccination in patients with haematological malignancy remains controversial [48] recent conclusions have been that patients with cancer receiving chemotherapy are able to respond to influenza vaccination, and because this intervention is safe, inexpensive, and widely available, vaccination for seasonal influenza and the novel H1N1 strain is indicated [51]. According to the IDSA guidelines yearly influenza vaccination with inactivated 
vaccine is recommended for all patients being treated for cancer [20].

Pulmonary aspergillosis is the major cause of fungal induced mortality in patients with haematological malignancies but organisms such as Candida species, Trichosporon species, Cryptococcus species, and Pneumocystis jirovecii may also cause fungal pneumonia [52].

\section{OTHER VIRAL INFECTIONS}

Herpes simplex viruses (HSV) are common complications among patients with haematological malignancies who are undergoing stem-cell transplantation or receiving myelosuppressive chemotherapy. Up to $80 \%$ of adult patients with leukaemia are HSV seropositive and the incidence of HSV lesions among seropositive patients receiving chemotherapy for acute leukaemia has been found to be above $60 \%$ [53]. The risk of HSV disease after allogeneic stem cell transplantation without prophylaxis is approximately $80 \%$ [54]. This relates almost exclusively to virus reactivations during the first few weeks after stem cell transplantation during bone marrow aplasia or in the presence of stomatitis [53].

In varicella-zoster virus (VZV)-seropositive recipients of bone marrow transplantation the risk of devoping herpes zoster between 3-12 months after the transplantation is 10$68 \%$ [53]. Prophylactic antiviral treatment has been shown to reduce the incidence of VZV infections in the pre- and postengraftment period, but in only one trial that examined the effect of antiviral treatment during episodes of intensive chemotherapy no effect was reported [55].

In the absence of effective antiviral prophylaxis, the incidence of Cytomegalovirus (CMV) infection among patients with haematological malignancy ranges from $5-75 \%$ [56]. T-cell function is paramount in the control of CMV, and T-cell depleting agents (e.g., alemtuzumab) and aggressive chemotherapy appear to increase the risk of CMV infection and disease [48]. The incidence of CMV infection and disease is less clearly defined for patients with haematological malignancies who receive conventional therapy. Investigators at the MD Anderson Cancer Center have reported an overall increase in CMV gastrointestinal disease [57], and CMV pneumonia among patients with lymphoma [58] and acute leukemia [59]. In the absence of effective antiviral prophylaxis, the incidence of CMV infection among patients with haematological malignancy ranges from 5-75\%. Late CMV infection after haematopoietic stem cell transplant is seen in $3-17 \%$ of allogeneic transplant recipients [60].

\section{GASTROINTESTINAL INFECTIONS}

Neutropenic enterocolitis (in the early 1970's referred to as typhilits) is the most important clinical entity among abdominal infections in neutropenic adults [61]. This acute inflammatory disease may involve coecum, colon, and the terminal part of ileum. Neutropen enterocolitis is reported to occur in $0.8 \%$ to $26 \%$ of neutropenic episodes and the case fatality has been reported to be $50 \%$ or higher [61]. The clinical presentation of neutropen enterocolitis is broad with patients with proven imaging findings having more severe disease [62]. The need for radiological confirmation is discussed but recommended by many authors [61]. Patients with mural thickening detected sonographically or by computerized tomography scan have a poorer prognosis than patients without this finding [63].

\section{TIME SINCE HAEMATOLOGICAL MALIGNANCY DIAGNOSIS AND RISK OF INFECTION}

Little is known about the risk of infections among longterm survivors of haematological malignancies. Gradel et al. found that, compared with the background population, patients with haematological malignancies had a 7-8 fold risk of hospitalisation with Salmonella or Campylobacter gastroenteritis in the 2 years after their malignancy diagnosis and a 4-5 fold increased risk in the period 3-5 years after malignancy diagnosis [64]. This study thus suggested an increased long-term risk of infection but the study did not distinguish between patients who were in remission and patients with active disease. Teodorescu et al. followed 209 patients who were diagnosed with hairy cell leukemia in the period from January 1997 to August 2007 in Denmark for a median of 4.5 years [65]. Compared with an age and sexmatched general population cohort patients with hairy cell leukemia had an increased risk of hospitalisation with pneumonia or bacteraemia [65]. The adjusted RR of infection was 8.04 (95\% CI: 4.99-12.95) the first year after diagnosis and 1.17 (95\% CI: 0.71-1.94) for the remaining follow-up period. This suggested that more than one year after diagnosis patients with hairy cell leukemia have a similar risk of infections as the general population.

\section{CONCLUSION}

Despite improved survival during the last decades patients with haematological malignancies are still at high risk of infectious complications. Bacteraemia and candidaemia are serious complications and the use of prophylaxis may lead to a higher prevalence of more resistant strains. Viral complications are most common following bone marrow transplantation. Little is known about the risk of infection in long-term survivors.

\section{ACKNOWLEDGEMENT}

Declared none.

\section{CONFLICT OF INTEREST}

The authors confirm that this article content has no conflicts of interest.

\section{REFERENCES}

[1] Crawford J, Dale DC, Lyman GH. Chemotherapy-induced neutropenia: risks, consequences, and new directions for its management. Cancer 2004; 100: 228-37.

[2] Naik JD, Sathiyaseelan SR, Vasudev NS. Febrile neutropenia. BMJ 2010; 341: c6981.

[3] Riis P. The cytology of inflammatory exudate: A study on normal subjects and on patients showing quantitative or qualitative changes of the white blood picture. Denmark: Munksgaard 1959.

[4] Bodey GP, Buckley M, Sathe YS, Freireich EJ. Quantitative relationships between circulating leukocytes and infection in patients with acute leukemia. Ann Intern Med 1966; 64: 328-40.

[5] Klastersky J. Science and pragmatism in the treatment and prevention of neutropenic infection. J Antimicrob Chemother 1998; 41 (Suppl D): 13-24.

[6] Bodey GP. Epidemiological studies of Pseudomonas species in patients with leukemia. Am J Med Sci 1970; 260: 82-9. 
[7] Bodey GP, NIES BA, Freireich EJ. Multiple organism septicemia in acute leukemia; analysis of 54 epidsodes. Arch Intern Med 1965; 116: 266-72.

[8] Mccabe WR, Jackson GG. Gram-Negative Bacteremia. 1. Etiology and Ecology. Arch Intern Med 1962; 110: 63-75.

[9] Schimpff S, Satterlee W, Young VM, Serpick A. Empiric therapy with carbenicillin and gentamicin for febrile patients with cancer and granulocytopenia. N Engl J Med 1971; 284: 1061-5.

[10] Klastersky J, Zinner SH, Calandra T, et al. Empiric antimicrobial therapy for febrile granulocytopenic cancer patients: lessons from four EORTC trials. Eur J Cancer Clin Oncol 1988; 24 (Suppl 1): S35-S45.

[11] Ceftazidime combined with a short or long course of amikacin for empirical therapy of gram-negative bacteremia in cancer patients with granulocytopenia. The EORTC International Antimicrobial Therapy Cooperative Group. N Engl J Med 1987; 317: 1692-8.

[12] Klastersky J, Glauser MP, Schimpff SC, Zinner SH, Gaya H. Prospective randomized comparison of three antibiotic regimens for empirical therapy of suspected bacteremic infection in febrile granulocytopenic patients. Antimicrob Agents Chemother 1986; 29: 263-70.

[13] Combination of amikacin and carbenicillin with or without cefazolin as empirical treatment of febrile neutropenic patients. The International Antimicrobial Therapy Project Group of the European Organisation for Research and Treatment of Cancer. J Clin Oncol 1983; 1: 597-603.

[14] Gram-positive bacteraemia in granulocytopenic cancer patients. EORTC International Antimicrobial Therapy Cooperative Group. Eur J Cancer 1990; 26: 569-74.

[15] Viscoli C, Cometta A, Kern WV, et al. Piperacillin-tazobactam monotherapy in high-risk febrile and neutropenic cancer patients. Clin Microbiol Infect 2006; 12: 212-6.

[16] Talcott JA, Siegel RD, Finberg R, Goldman L. Risk assessment in cancer patients with fever and neutropenia: a prospective, twocenter validation of a prediction rule. J Clin Oncol 1992; 10: 31622.

[17] Klastersky J, Paesmans M, Rubenstein EB, et al. The Multinational Association for Supportive Care in Cancer risk index: A multinational scoring system for identifying low-risk febrile neutropenic cancer patients. J Clin Oncol 2000; 18: 3038-51.

[18] Klastersky J, Ameye L, Maertens J, et al. Bacteraemia in febrile neutropenic cancer patients. Int J Antimicrob Agents 2007; 30 (Suppl 1): S51-S59.

[19] Cherif H, Johansson E, Bjorkholm M, Kalin M. The feasibility of early hospital discharge with oral antimicrobial therapy in low risk patients with febrile neutropenia following chemotherapy for haematologic malignancies. Haematologica 2006; 91: 215-22.

[20] Freifeld AG, Bow EJ, Sepkowitz KA, et al. Clinical practice guideline for the use of antimicrobial agents in neutropenic patients with cancer: 2010 Update by the Infectious Diseases Society of America. Clin Infect Dis 2011; 52: 427-31.

[21] Schimpff SC, Gaya H, Klastersky J, Tattersall MH, Zinner SH. Three antibiotic regimens in the treatment of infection in febrile granulocytopenic patients with cancer. The EORTC international antimicrobial therapy project group. J Infect Dis 1978; 137: 14-29.

[22] Marchetti O, Calandra T. Infections in neutropenic cancer patients. Lancet 2002; 359: 723-5.

[23] Carratala J, Gudiol F. Changing epidemiology of bacterial infection in neutropenic patients with cancer. Antibiot Chemother 2000; 50: $1-9$.

[24] Nørgaard M, Larsson H, Pedersen G, Schønheyder HC, Sørensen HT. Haematological malignancies-a predictor of a poor outcome in patients with bacteraemia. J Infect 2006; 53: 190-8

[25] Pittet D, Li N, Woolson RF, Wenzel RP. Microbiological factors influencing the outcome of nosocomial bloodstream infections: a 6year validated, population-based model. Clin Infect Dis 1997; 24: 1068-78.

[26] Zinner SH. Changing epidemiology of infections in patients with neutropenia and cancer: emphasis on gram-positive and resistant bacteria. Clin Infect Dis 1999; 29: 490-4.

[27] Ramphal R. Changes in the etiology of bacteremia in febrile neutropenic patients and the susceptibilities of the currently isolated pathogens. Clin Infect Dis 2004; 39 (Suppl 1): S25-31.

[28] Chen CY, Tsay W, Tang JL, et al. Epidemiology of bloodstream infections in patients with haematological malignancies with and without neutropenia. Epidemiol Infect 2010; 138: 1044-51.
[29] Gupta A, Singh M, Singh H, et al. Infections in acute myeloid leukemia: an analysis of 382 febrile episodes. Med Oncol 2010; 27 : $1037-45$.

[30] Rolston KV. Challenges in the treatment of infections caused by gram-positive and gram-negative bacteria in patients with cancer and neutropenia. Clin Infect Dis 2005; 40 (Suppl 4): S246-52.

[31] Swati M, Gita N, Sujata B, Farah J, Preeti M. Microbial etiology of febrile neutropenia. Indian J Hematol Blood Transfus 2010; 26: 4955 .

[32] Bhusal Y, Mihu CN, Tarrand JJ, Rolston KV. Incidence of fluoroquinolone-resistant and extended-spectrum beta-lactamaseproducing Escherichia coli at a comprehensive cancer center in the United States. Chemotherapy 2011; 57: 335-8.

[33] Trecarichi EM, Tumbarello M, Spanu T, et al. Incidence and clinical impact of extended-spectrum-beta-lactamase (ESBL) production and fluoroquinolone resistance in bloodstream infections caused by Escherichia coli in patients with haematological malignancies. J Infect 2009; 58: 299-307.

[34] Nørgaard M, Larsson H, Pedersen G, Schønheyder HC, Sørensen HT. Risk of bacteraemia and mortality in patients with haematological malignancies. Clin Microbiol Infect 2006; 12: 217 23.

[35] Williams MD, Braun LA, Cooper LM, et al. Hospitalised cancer patients with severe sepsis: analysis of incidence, mortality, and associated costs of care. Crit Care 2004; 8: R291-8.

[36] Ruescher TJ, Sodeifi A, Scrivani SJ, Kaban LB, Sonis ST. The impact of mucositis on alpha-hemolytic streptococcal infection in patients undergoing autologous bone marrow transplantation for haematologic malignancies. Cancer 1998; 82: 2275-81.

[37] Marr KA, Seidel K, White TC, Bowden RA. Candidemia in allogeneic blood and marrow transplant recipients: evolution of risk factors after the adoption of prophylactic fluconazole. J Infect Dis 2000; 181: 309-16.

[38] Bustamante CI, Wade JC. Herpes simplex virus infection in the immunocompromised cancer patient. J Clin Oncol 1991; 9: 190315 .

[39] Teira R, Lizarralde E, Santamaria JM, et al. [Incidence of bacteremia among histologic groups of haematologic malignancies]. Enferm Infecc Microbiol Clin 2003; 21: 24-9.

[40] Pagano L, Tacconelli E, Tumbarello M, et al. Bacteremia in patients with haematological malignancies. Analysis of risk factors, etiological agents and prognostic indicators. Haematologica 1997; 82: 415-9.

[41] Pedersen G, Nørgaard M, Kiiveri M, et al. Risk of bacteremia in patients with haematological and other malignancies after initial placement of a central venous catheter. J Long Term Eff Med Implants 2007; 17: 303-11.

[42] Bucaneve G, Micozzi A, Menichetti F, et al. Levofloxacin to prevent bacterial infection in patients with cancer and neutropenia. N Engl J Med 2005; 353: 977-87.

[43] Apostolopolou E, Raftopoulos V, Terzis K, Pissaki K, Pagoni M, Delibasi S. Infection probability score, APACHE II and KARNOFSKY scoring systems as predictors of infection onset in haematology-oncology patients. J Clin Nurs 2010; 19: 1560-8.

[44] Sipsas NV, Lewis RE, Tarrand J, et al. Candidemia in patients with haematologic malignancies in the era of new antifungal agents (2001-2007): stable incidence but changing epidemiology of a still frequently lethal infection. Cancer 2009; 115: 4745-52.

[45] Marr KA, White TC, van Burik JA, Bowden RA. Development of fluconazole resistance in Candida albicans causing disseminated infection in a patient undergoing marrow transplantation. Clin Infect Dis 1997; 25: 908-10.

[46] Guven GS, Uzun O, Cakir B, Akova M, Unal S. Infectious complications in patients with haematological malignancies consulted by the Infectious Diseases team: a retrospective cohort study (1997-2001). Support Care Cancer 2006; 14: 52-5.

[47] Puig N, De La RJ, Jarque I, et al. Characteristics of and risk factors for pneumonia in patients with haematological malignancies developing fever after autologous blood stem cell transplantation. Leuk Lymphoma 2007; 48: 2367-74.

[48] Wade JC. Viral infections in patients with haematological malignancies. Hematology Am Soc Hematol Educ Program 2006; 368-74.

[49] Parody R, Rabella N, Martino R, et al. Upper and lower respiratory tract infections by human enterovirus and rhinovirus in adult 
patients with haematological malignancies. Am J Hematol 2007; 82: 807-11.

[50] Schnell D, Mayaux J, de BC, et al. Risk factors for pneumonia in immunocompromised patients with influenza. Respir Med 2010; 104: 1050-6.

[51] Pollyea DA, Brown JM, Horning SJ. Utility of influenza vaccination for oncology patients. J Clin Oncol 2010; 28: 2481-90.

[52] Pagano L, Caira M, Candoni A, et al. The epidemiology of fungal infections in patients with haematologic malignancies: the SEIFEM-2004 study. Haematologica 2006; 91: 1068-75.

[53] Styczynski J, Reusser P, Einsele H, et al. Management of HSV, VZV and EBV infections in patients with haematological malignancies and after SCT: guidelines from the Second European Conference on Infections in Leukemia. Bone Marrow Transplant 2009; 43: 757-70.

[54] Meyers JD, Flournoy N, Thomas ED. Infection with herpes simplex virus and cell-mediated immunity after marrow transplant. J Infect Dis 1980; 142: 338-46.

[55] Yahav D, Gafter-Gvili A, Muchtar E, et al. Antiviral prophylaxis in haematological patients: systematic review and meta-analysis. Eur J Cancer 2009; 45: 3131-48.

[56] Boeckh M, Nichols WG. The impact of cytomegalovirus serostatus of donor and recipient before hematopoietic stem cell transplantation in the era of antiviral prophylaxis and preemptive therapy. Blood 2004; 103: 2003-8.

[57] Torres HA, Kontoyiannis DP, Bodey GP, et al. Gastrointestinal cytomegalovirus disease in patients with cancer: a two decade experience in a tertiary care cancer center. Eur J Cancer 2005; 41: 2268-79.

[58] Chemaly RF, Torres HA, Hachem RY, et al. Cytomegalovirus pneumonia in patients with lymphoma. Cancer 2005; 104: 1213-20.

[59] Nguyen Q, Estey E, Raad I, et al. Cytomegalovirus pneumonia in adults with leukemia: an emerging problem. Clin Infect Dis 2001; 32: 539-45.

[60] Boeckh M, Leisenring W, Riddell SR, et al. Late cytomegalovirus disease and mortality in recipients of allogeneic hematopoietic stem cell transplants: importance of viral load and T-cell immunity. Blood 2003; 101: 407-14.

[61] Gorschluter M, Mey U, Strehl J, et al. Neutropenic enterocolitis in adults: systematic analysis of evidence quality. Eur J Haematol 2005; $75: 1-13$.

[62] Gomez L, Martino R, Rolston KV. Neutropenic enterocolitis: spectrum of the disease and comparison of definite and possible cases. Clin Infect Dis 1998; 27: 695-9.

[63] Cartoni C, Dragoni F, Micozzi A, et al. Neutropenic enterocolitis in patients with acute leukemia: prognostic significance of bowel wall thickening detected by ultrasonography. J Clin Oncol 2001; 19: 756-61.

[64] Gradel KO, Nørgaard M, Dethlefsen C, et al. Increased risk of zoonotic Salmonella and Campylobacter gastroenteritis in patients with haematological malignancies: a population-based study. Ann Hematol 2009; 88: 761-7.

[65] Teodorescu M, Engebjerg MC, Johansen P, Nørgaard M, Gregersen $\mathrm{H}$. Incidence, risk of infection and survival of hairy cell leukaemia in Denmark. Dan Med Bull 2010; 57: A4216.

(C) Mette Nørgaard; Licensee Bentham Open.

This is an open access article licensed under the terms of the Creative Commons Attribution Non-Commercial License (http: //creativecommons.org/licenses/by$\mathrm{nc} / 3.0 /$ ) which permits unrestricted, non-commercial use, distribution and reproduction in any medium, provided the work is properly cited. 